\title{
Actualización de las precauciones estándar y específicas de aislamiento para la prevención de las infecciones asociadas a la atención en salud
}

\section{Update of the standard and specific isolation precautions for the prevention of infections associated with health care}

\author{
Giancarlo Hernán Cristerna-Tarrasa, ${ }^{1}$ Hilda Hernández-Orozco, ${ }^{2}$ Eduardo Arias-de la Garza, ${ }^{2}$ Napoleón González- \\ Saldaña ${ }^{3}$
}

\begin{abstract}
Resumen
Las infecciones asociadas con la atención en salud son un problema grave en los hospitales a nivel mundial. La Organización Mundial de la Salud (OMS) estima que el $7 \%$ de los pacientes hospitalizados en países industrializados y el $10 \%$ en países en vías de industrialización sufrirá infecciones asociadas con la atención en salud. Estas infecciones se asocian con aumento significativo de la morbilidad y mortalidad, y los costos en la atención de la salud y están estrechamente relacionadas con la estancia hospitalaria prolongada, el uso de dispositivos intravasculares, catéteres urinarios, intubación orotraqueal, ventilación mecánica, entre otros. Además, en años recientes, los microorganismos resistentes a múltiples fármacos son frecuentemente aislados en las infecciones asociadas con la atención en salud, lo que contribuye al aumento significativo de la morbilidad y mortalidad, administración de antimicrobianos de amplio espectro y costos médicos.

Se han hecho esfuerzos en todo el mundo para reducir las infecciones asociadas con la atención en salud al asumir precauciones específicas de aislamiento basadas en el tipo de microorganismo, transmisión y susceptibilidad antimicrobiana. Estos se basan en un alto porcentaje de cumplimiento de higiene de manos del personal de salud, rápida identificación de las infecciones asociadas con la atención en salud y la implementación de las precauciones específicas de aislamiento para prevenir brotes. Estas medidas incluyen tres mecanismos principales de trasmisión: contacto, gotas y vía aérea. Este estudio muestra la actualización de las recomendaciones publicadas en 2009 para prevenir las infecciones asociadas con la atención en salud, de acuerdo con la epidemiología local y las recomendaciones más recientes de la OMS y de los Centros de Control de Enfermedades (CDC).

PALABRAS CLAVE: Infecciones asociadas con la atención en salud; hospitales; Organización Mundial de la Salud; precauciones específicas de aislamiento; países industrializados; catéter urinario; intubación orotraqueal; ventilación mecánica; fármacos; morbilidad; antibióticos; personal de salud; Centros de Control de Enfermedades.
\end{abstract}

\section{Abstract}

Health Care Associated Infections (HAIs) are a mayor problem in hospitals around the World. The World Health Organization (WHO) estimates that $7 \%$ of patients hospitalized in developed countries and $10 \%$ in developing countries will develop a HAI. These infections are related with a significant rise in morbimortality and health care costs. Infections are mostly associated with prolonged length of stay, intravascular devices, permanent urinary catheters, orotracheal intubation and use of mechanical ventilation among others. In addition, in recent years Multi Drug Resistant (MDR) organisms are often isolated in HAls, which contributes to the significantly rise in morbidity, mortality, use of broader spectrum antimicrobials and cost. Efforts around the world are destined to reduce HAIs by using specific isolation precautions regarding the type of microorganism, its transmission and its drug susceptibility. These are primarily based on a high percentage of health care workers correct hand-wash, fast and adequate identification
${ }^{1}$ Residente de Infectología Pediátrica. ${ }^{2}$ Médico adscrito de Infectología pediátrica y al Comité de Infecciones Asociadas a la Atención en Salud. ${ }^{3}$ Jefe del Departamento de Infectología pediátrica.

Instituto Nacional de Pediatría, Ciudad de México.

Recibido: 4 de febrero 2020

Aceptado: 12 de noviembre 2020

Correspondencia

Giancarlo Hernán Cristerna Tarrasa

ghct.inp@gmail.com

Este artículo debe citarse como: Cris terna Tarrasa GH, HernándezOrozco H, Arias de la Garza E, González Saldaña N. Actualización de las precauciones estándar y específicas de aislamiento para la prevención de las infecciones asociadas a la atención en salud. Acta Pediatr Méx 2021; 42 (2): 74-84. DOI: http://dx.doi.org/10.18233/APM42No2pp74-841981 
of HAls and subsequently, the specific isolation recommendation to further prevent outbreaks. These measures are based on the three main transmission methods: contact precautions, droplet precautions and airborne precautions. Therefore, we present an actualization of the 2009 recommendations for prevention of HAls according to our local epidemiology and to the latest WHO and the Centers for Disease Control (CDC) recommendations.

KEYWORDS: Health Care Associated Infections; Hospitals; World Health Organization; Specific isolation precautions; Developed countries; Urinary catheter; Orotraqueal intubation; Mechanical ventilation; Drugs; Morbidity; Antimicrobials; Health care workers; Centers for Disease Control.

\section{ANTECEDENTES}

Las infecciones asociadas con la atención en salud son un problema importante de las unidades de atención médica. ${ }^{1}$ La Organización Mundial de la Salud estima que en $7 \%$ de los pacientes de países industrializados y en $10 \%$ de localidades en vías de industrialización ocurre, mínimo, una infección asociada con la atención en salud durante la hospitalización; y uno de los factores de riesgo más importantes es la transmisión intrahospitalaria. Estas infecciones se asocian con mayor morbilidad y mortalidad, y aumento significativo de los costos de atención en salud. ${ }^{2}$

Las infecciones asociadas con la atención en salud descritas con mayor frecuencia en Estados Unidos son: infección del torrente sanguíneo asociada con el catéter, infección de vías urinarias asociadas con el catéter, infecciones del sitio quirúrgico y neumonía relacionada con los cuidados de la salud, que incluye a la asociada o no con ventilador, entre otras. ${ }^{3}$ Además, en los últimos años han cobrado gran relevancia las infecciones asociadas con la atención en salud por microorganismos resistentes a múltiples fármacos, principalmente los del acrónimo ESKAPE (Enterococcus faecium resistente a vancomicina, Stapylococcus aureus resistente a meticilina (MRSA por sus siglas en inglés), Klebsiella pneumoniae, Acinetobacter baumannii, Pseudomonas aeruginosa y Enterobacter spp), pues las infecciones asociadas con estos son de mayor gravedad y, por los mecanismos de resistencia antimicrobiana, el tratamiento se encuentra limitado. ${ }^{4}$
En el Instituto Nacional de Pediatría se reporta una tasa de infecciones asociadas con la atención en salud de 7.9 por cada 1000 días paciente. Las más frecuentes, en forma decreciente, son la infección del torrente sanguíneo, neumonía, infección de vías urinarias, infección del sitio quirúrgico y gastroenteritis. Los diez microorganismos más frecuentemente aislados, reportados en forma decreciente, son: Escherichia coli, Pseudomonas aeruginosa, Klebsiella pneumoniae, Enterococus faecalis, Staphylococcus epidermidis, Candida albicans, Staphylococcus aureus, Enterococcus cloacae y Enterococcus faecium.

\section{FACTORES RELACIONADOS CON LA TRANSMISIÓN}

En el año 2007, los Centros de Control de Enfermedades (CDC por sus siglas en inglés) ${ }^{5}$ publicaron una guía para disminuir los riesgos de transmisión de infecciones asociadas con la atención en salud, con última actualización en julio de 2019. Sin embargo, se observan cambios en las medidas de aislamiento secundarias a las modificaciones de las características de los microorganismos, su multirresistencia antimicrobiana y relación con el medio ambiente. Por ello, el objetivo de este documento es informar la actualización de las precauciones específicas de aislamiento, de acuerdo con las condiciones descritas.

En la guía de los CDC se describen algunas características importantes y tres modos de transmisión de los agentes infectantes: 
1. Fuentes o reservorio: Derivados de personas (pacientes, personal de salud, familiares, etc.), equipo médico contaminado o ambiente hospitalario. En el caso de fuentes de infección humana, es importante conocer los periodos de incubación de los diferentes patógenos para la valoración del contacto. La microbiota endógena también provoca infecciones asociadas con la atención en salud, considerada de difícil prevención.

2. Huésped susceptible: Si bien todo paciente que se encuentra hospitalizado es un huésped susceptible, existe mayor riesgo en inmunodeprimidos, con larga estancia hospitalaria, rotura de la integridad cutánea o membranas mucosas, incluso la implementación de múltiples métodos invasivos (tubo endotraqueal, sonda pleural, sonda urinaria, catéter venoso central, venoclisis, etc.) y administración de medicamentos que alteran la microbiota e inmunosupresión (antibióticos, antiácidos, esteroides, inmunosupresores).

3. Modo de transmisión: Se definen tres modos principales:

a. Contacto. Puede ser directo o indirecto. El directo se refiere cuando el contagio ocurre sin ningún intermediario, es decir, el contacto entre una persona enferma con una susceptible; mientras que el indirecto existe con uno o varios intermediarios, objetos o personas contaminados o infectados. Los medios de contagio directo incluyen contacto con sangre, fluidos corporales, piel en los casos de escabiasis, virus de herpes simple, incluso sífilis. En el caso de contacto indirecto se reportan, como medios de contagio, las manos del personal de salud, equipo médico (estetoscopio), juguetes, instrumental diagnóstico (endoscopios) o quirúrgico contaminados posterior a la atención de un paciente infectado o colonizado. Además, la ropa médica se considera fómite y posible vector de transmisión de patógenos hospitalarios, como: microorganismos resistentes a multiples fármacos, Enterococcus faecium resistente a vancomicina o Clostridioides difficile, previamente Ilamado Clostridium difficile (C. difficile).

b. Gotas. Implica la transmisión a través de gotas de secreciones; en este tipo de transmisión, los agentes infecciosos viajan por el aire a corta distancia y al hacer contacto con las mucosas del huésped susceptible se genera el contagio. La transmisión ocurre por gotas: al toser, estornudar o hablar. Otras formas de contagio son: al hacer procedimientos dentales, succión de secreciones, intubación traqueal o reanimación cardiopulmonar. Se describe, clásicamente, que la distancia de contagio es de 1.5 metros. El tamaño de las partículas de contagio por medio de gotas es mayor de 5 micrómetros de diámetro y contienen microorganismos que no sobreviven mucho tiempo suspendidos en el aire. Algunos agentes infecciosos que se transmiten por gotas incluyen: $B$. pertussis, M. pneumoniae, N. meningitidis, virus influenza, SARS-CoV-2, adenovirus, rinovirus, entre otros.

c. Aérea. La base de este tipo de transmisión es la diseminación de partículas infectantes que sobreviven largos periodos suspendidas en el aire, en microgotas menores de 5 micrones. Se ha descrito que estas partículas viajan distancias largas por medio de corrientes de aire y pueden inhalarse por el individuo susceptible. Entre los microorganismos más frecuentes se encuentran: M. tuberculosis, Aspergillus spp, virus del sarampión y virus de la varicela-zoster. Otros microorganismos que pueden transmitirse y propagarse rá- 
pidamente por vía aérea en circunstancias especiales son: coronavirus ([SARS, por sus siglas en inglés, en especial el actual causante de la pandemia de COVID-19 (SARS-CoV-2)]), las esporas de B. anthracis, entre otros.

\section{INDICACIONES DE AISLAMIENTO}

Para los agentes patógenos comentados con capacidad de dispersarse con mayor facilidad a través de las manos, ropa, contacto cercano, incluso por el aire, existen medidas y equipo médico protector para cada una de las situaciones, que se resumen en el Cuadro 1.

El Instituto Nacional de Pediatría cuenta con el Comité de Prevención y Control de Infecciones Asociadas con la Atención de la Salud y su Unidad Operativa. Su algoritmo de respuesta se basa en el reporte inmediato de un caso sospechoso o confirmado de alguna enfermedad potencialmente transmisible, con el consiguiente aislamiento específico para cada enfermedad y, por tanto, detener la propagación del agente infeccioso, con la intención de disminuir el riesgo de complicaciones en los pacientes, además de la reducción de costos de atención médica y evitar brotes.
Las medidas de prevención pueden ser las de referencia, que se aplican a todos los pacientes dependiendo del procedimiento de atención que se realice y las precauciones específicas de aislamiento, según la sospecha o diagnóstico confirmado de alguna infección específica, estas últimas se dividen según el método de transmisión relacionado con el agente sospechado o confirmado. Cuadro 2

Algunos reportes describen que al implementar las medidas de aislamiento existe desatención y sensación de exclusión al paciente, incluso aumenta el riesgo de complicaciones, porque el personal de salud disminuye la cantidad de veces en la visita y atención del paciente, lo que puede implicar una disminución en la calidad de la atención. Por tal motivo, existen indicaciones específicas para el aislamiento de los pacientes, dependiendo del tipo de infección; debe valorarse la duración del aislamiento al menor tiempo posible que elimine la cadena de transmisión. Tener un paciente aislado durante menos tiempo del requerido aumenta el riesgo de contagio intrahospitalario. Exceder el tiempo de aislamiento aumenta los costos y dificulta la movilidad de los pacientes dentro del hospital. La identificación de microorganismos multirresistentes, deficiencia en los servicios de

Cuadro 1. Equipo protector e indicaciones para disminuir el riesgo de infecciones asociadas con la atención en salud y contagio en el personal, pacientes y visitantes

\begin{tabular}{|l|l|}
\hline $\begin{array}{l}\text { Equipo o medida de protección } \\
\text { Agua con jabón }\end{array}$ & $\begin{array}{l}\text { Cinco momentos de higiene de manos, específicamente cuando están visiblemente } \\
\text { sucias, o cuando los pacientes están infectados por Clostridioides difficile u otros mi- } \\
\text { croorganismos esporulados. }\end{array}$ \\
\hline Solución alcoholada 70\% & Cinco momentos de higiene de manos. \\
\hline Guantes & Contacto con sangre, secreciones, membranas mucosas y equipo contaminado. \\
\hline Mascarilla quirúrgica-cubrebocas & $\begin{array}{l}\text { Procedimientos en los que puede salpicar sangre o secreciones corporales, como medida } \\
\text { de precauciones estándar, aislamiento protector (precauciones estándar) o aislamiento } \\
\text { de gotas (precaución especifica de aislamiento). }\end{array}$ \\
\hline Mascarilla N95 & $\begin{array}{l}\text { Pacientes con tuberculosis pulmonar bacilífera. Procedimientos que generen aerosoles } \\
\text { en el diagnóstico confirmado de SARS-CoV-2 (precauciones en la vía aérea). }\end{array}$ \\
\hline Batas protectoras & $\begin{array}{l}\text { Protección de piel y ropa contra sangre o secreciones corporales, como medida de } \\
\text { precauciones estándar, aislamiento protector, de contacto, gotas y vía aérea. }\end{array}$
\end{tabular}


Cuadro 2. Precauciones estándar (PE) y precauciones específicas de aislamiento (PEA)

\begin{tabular}{|c|c|c|}
\hline Medida & Equipo y Acciones & Ejemplos \\
\hline $\begin{array}{l}\text { Precauciones } \\
\text { estándar }\end{array}$ & $\begin{array}{l}\text { Higiene de manos, guantes no estériles para la } \\
\text { manipulación de secreciones, mascarilla quirúrgica- } \\
\text { cubrebocas, bata }\end{array}$ & $\begin{array}{l}\text { Todos los pacientes, dependiendo del procedi- } \\
\text { miento de atención a realizar }\end{array}$ \\
\hline $\begin{array}{l}\text { Precaución de } \\
\text { referencia: aisla- } \\
\text { miento para preve- } \\
\text { nir la infección }\end{array}$ & $\begin{array}{l}\text { Higiene de manos, mascarilla quirúrgica-cubrebocas, } \\
\text { bata }\end{array}$ & $\begin{array}{l}\text { Guía de pacientes con menos de } 500 \text { neutrófilos. } \\
\text { Otros aislamientos por consenso de los servicios } \\
\text { de Hematología, Oncología, Inmunología, UT- } \\
\text { CHP del Instituto Nacional de Pediatría. }\end{array}$ \\
\hline $\begin{array}{l}\text { Precaución espe- } \\
\text { cífica de aisla- } \\
\text { miento: contacto } \\
\text { (C) }\end{array}$ & $\begin{array}{l}\text { Higiene de manos, bata protectora, guantes no es- } \\
\text { tériles para el manejo de secreciones o excreciones }\end{array}$ & $\begin{array}{l}\text { Gastroenteritis aguda, diarrea por C. difficile, } \\
\text { pediculosis. }\end{array}$ \\
\hline $\begin{array}{l}\text { Precaución espe- } \\
\text { cífica de aisla- } \\
\text { miento: } \operatorname{gotas}(\mathbf{G})\end{array}$ & $\begin{array}{l}\text { Higiene de manos, uso de mascarilla quirúrgica- } \\
\text { cubrebocas, bata protectora, uso de guantes no } \\
\text { estériles para el manejo de secreciones }\end{array}$ & $\begin{array}{l}\text { Influenza, tos ferina, parotiditis, parvovirus B19, } \\
\text { meningococo, Streptococcus pyogenes S. } \beta \text { - he- } \\
\text { molítico del grupo A (SBHGA), SARS-CoV- } 2 \text {. }\end{array}$ \\
\hline $\begin{array}{l}\text { Precaución espe- } \\
\text { cífica de aisla- } \\
\text { miento: aéreo (A) }\end{array}$ & $\begin{array}{l}\text { Higiene de manos, uso de mascarilla N95 (tubercu- } \\
\text { losis, SARS-CoV-2), bata protectora, uso de guantes } \\
\text { para la manipulación de secreciones. Habitación } \\
\text { con puerta cerrada, idealmente con presión negativa }\end{array}$ & $\begin{array}{l}\text { Tuberculosis pulmonar o extrapulmonar en caso } \\
\text { de supuración abundante, sarampión, SARS- } \\
\text { CoV-2 en procedimientos que generan aerosoles } \\
\text { o circunstancias especiales. }\end{array}$ \\
\hline $\begin{array}{l}\text { Precausión especí- } \\
\text { fica de aislamien- } \\
\text { to: mixto }(\mathbf{M})\end{array}$ & $\begin{array}{l}\text { Contacto y vía aérea, higiene de manos, uso de } \\
\text { mascarilla quirúrgica-cubrebocas de rutina, bata } \\
\text { protectora, uso de guantes para la manipulación de } \\
\text { secreciones }\end{array}$ & $\begin{array}{l}\text { Varicela y herpes zoster diseminado, o en pacien- } \\
\text { tes inmunodeprimidos }\end{array}$ \\
\hline
\end{tabular}

limpieza hospitalaria, falta de espacio y hacinamiento han ocasionado que se requieran, en ocasiones, conductas de aislamiento hasta el egreso del paciente, porque lo más importante es evitar la cadena de transmisión y los brotes intrahospitalarios.

Existen más de 100 tipos de aislamientos dirigidos a cada una de las enfermedades infecciosas conocidas hasta el momento; en el Cuadro 3 se enlistan los más importantes en el ámbito pediátrico..$^{5-12}$

Como parte de la vigilancia epidemiológica de los hospitales es importante contar con un registro de aislamiento de microorganismos resistentes a múltiples fármacos. En caso de identificar alguno, deben seguirse las precauciones específicas de aislamiento. Cuadro 4

Las precauciones estándar se aplican a todos los pacientes, e incluyen el aislamiento protector, que generalmente debe tener el paciente inmunodeprimido, con una cuenta menor de 500 neutrófilos; sin embargo, debido a la deficiente limpieza hospitalaria y condiciones y enfermedades del paciente en el Instituto Nacional de Pediatría, se analizó por un grupo interdisciplinario y se decidió que el aislamiento protector se aplicaría a los pacientes que se describen en el Cuadro 5.

\section{CONCLUSIONES}

Las medidas de aislamiento de precauciones estándar y específicas basadas en la transmisión, son necesarias para disminuir el riesgo de las infecciones asociadas con la atención en salud, las complicaciones y los costos de atención médica. Es importante identificar la enfermedad y su duración, para evitar el aislamiento tardío y el uso excesivo. Sin embargo, deben considerarse las condiciones de infraestructura, mantenimiento y medidas de control de un medio ambiente se- 
Cristerna-Tarrasa GH, et al. Infecciones asociadas con la atención en salud

Cuadro 3. Precauciones de aislamiento de acuerdo con infecciones o condiciones específicas ${ }^{5-11}$ (continúa en la siguiente página)

\begin{tabular}{|c|c|c|c|}
\hline Infección & $\begin{array}{l}\text { Tipo de } \\
\text { precaución }\end{array}$ & Duración & Consideraciones \\
\hline $\begin{array}{l}\text { Absceso supurativo (su- } \\
\text { puración importante) }\end{array}$ & C & $\begin{array}{l}\text { Hasta que se detenga la supuración o } \\
\text { se contenga por un vendaje }\end{array}$ & $\begin{array}{l}\text { Si la secreción está cubierta y contenido } \\
\text { por vendaje no es necesario el aislamiento }\end{array}$ \\
\hline Aspergilosis & $\mathrm{E}$ & No requiere aislamiento & No se transmite de persona a persona \\
\hline Bronquiolitis & E & No requiere aislamiento & $\begin{array}{l}\text { Uso de mascarilla, de acuerdo con las } \\
\text { precauciones estándar }\end{array}$ \\
\hline $\begin{array}{l}\text { Bacteriemias, bacilos } \\
\text { gramnegativos }\end{array}$ & E & No requiere aislamiento & $\begin{array}{l}\text { No aislar hasta conocer la sensibilidad } \\
\text { antimicrobiana }\end{array}$ \\
\hline Candidiasis & E & No requiere aislamiento & Incluir lesiones mucocutáneas \\
\hline C. difficile & C & $\begin{array}{l}\text { Inmunocompetentes: un mes y medio } \\
\text { de finalizar el tratamiento. } \\
\text { Inmunodeprimidos: } 6 \text { meses del fina- } \\
\text { lizar el tratamiento. }\end{array}$ & $\begin{array}{l}\text { Lavado de manos con agua y jabón. } \\
\text { Manipulación de heces con guantes. Uso } \\
\text { de hipoclorito de sodio a } 5000 \text { ppm para } \\
\text { limpieza de superficies y área al egreso } \\
\text { del paciente, o cuando se tenga opor- } \\
\text { tunidad por traslado, por diagnóstico o } \\
\text { tratamiento del paciente }\end{array}$ \\
\hline $\begin{array}{l}\text { Conjuntivitis aguda } \\
\text { bacteriana, Chlamydia } \\
\text { spp, N. gonorrhoeae }\end{array}$ & E & No requiere aislamiento & \\
\hline $\begin{array}{l}\text { Conjuntivitis aguda } \\
\text { viral } \\
\text { hemorrágica }\end{array}$ & $\mathrm{C}$ & Duración de la enfermedad & $\begin{array}{l}\text { Altamente contagiosa, principalmente en } \\
\text { hospitales pediátricos. Ocasiona brotes }\end{array}$ \\
\hline $\begin{array}{l}\text { Coronavirus estacio- } \\
\text { nales } \\
\text { (No SARS-CoV-2) } \\
\text { Síntomas respiratorios }\end{array}$ & G & Duración de la Enfermedad & \\
\hline $\begin{array}{l}\text { Coronavirus } \\
\text { (SARS-CoV-2) } \\
\text { Síntomas Respiratorios } \\
\text { Caso }\end{array}$ & G & $\begin{array}{l}\text { Al menos } 10 \text { días posterior al primer } \\
\text { síntoma y al menos } 24 \text { horas a febril } \\
\text { con mejoría de síntomas respiratorios }\end{array}$ & $\begin{array}{l}\text { Procedimientos que generan aerosoles. } \\
\text { Usar mascarilla N95 y protección ocular. } \\
\text { En pacientes inmunocomprometidos } \\
\text { pueden ser transmisores del virus por más } \\
\text { de } 20 \text { días. ( Referir Infectología) }\end{array}$ \\
\hline $\begin{array}{l}\text { Coronavirus } \\
\text { (SARS-CoV-2) } \\
\text { Contacto }\end{array}$ & G & $\begin{array}{l}10 \text { días a } 14 \text { días (evaluar tipo de } \\
\text { contacto) }\end{array}$ & \\
\hline Citomegalovirus CMV & E & No requiere aislamiento & Incluir neonatos e inmunodeprimidos \\
\hline Virus Epstein-Barr & $\mathrm{E}$ & No requiere aislamiento & Incluida la mononucleosis infecciosa \\
\hline $\begin{array}{l}\text { Gastroenteritis aguda } \\
\text { (viral no especificada) }\end{array}$ & C & $\begin{array}{l}\text { Hasta que cedan las evacuaciones } \\
\text { líquidas }\end{array}$ & $\begin{array}{l}\text { En caso de usar pañal o personas con in- } \\
\text { continencia anal o para control de brotes }\end{array}$ \\
\hline $\begin{array}{l}\text { Gastroenteritis aguda } \\
\text { (bacteriana no especi- } \\
\text { ficada) }\end{array}$ & $\mathrm{C}$ & $\begin{array}{l}\text { Hasta que cedan las evacuaciones } \\
\text { líquidas }\end{array}$ & $\begin{array}{l}\text { En caso de usar pañal o personas con in- } \\
\text { continencia anal o para control de brotes }\end{array}$ \\
\hline $\begin{array}{l}\text { Gastroenteritis por } \\
\text { Norovirus }\end{array}$ & $\mathrm{C}$ & $\begin{array}{l}\text { La eliminación del virus es prolonga- } \\
\text { da en inmunocomprometidos e inmu- } \\
\text { nocompetentes. Mantener aislamiento } \\
14 \text { días }\end{array}$ & $\begin{array}{l}\text { En caso de usar pañal o personas con in- } \\
\text { continencia anal o para control de brotes } \\
\text { Lavado de manos con agua y jabón. } \\
\text { Manipulación de heces con guantes. Uso } \\
\text { de hipoclorito de sodio a } 5000 \text { ppm para } \\
\text { limpieza de superficies y área sin presen- } \\
\text { cia del paciente }\end{array}$ \\
\hline
\end{tabular}




\begin{tabular}{|c|c|c|c|}
\hline $\begin{array}{l}\text { Gastroenteritis por } \\
\text { Rotavirus }\end{array}$ & $\mathrm{C}$ & $\begin{array}{l}\text { La eliminación del virus es prolonga- } \\
\text { da en pacientes inmunodeprimidos } \\
\text { e inmunocompetentes. Mantener } \\
\text { aislamiento por } 21 \text { días }\end{array}$ & $\begin{array}{l}\text { En caso de usar pañal o personas con in- } \\
\text { continencia anal o para control de brotes } \\
\text { La eliminación del virus es prolongada en } \\
\text { pacientes inmunodeprimidos e inmuno- } \\
\text { competentes hasta } 21 \text { días }\end{array}$ \\
\hline $\begin{array}{l}\text { Virus de hepatitis A } \\
\text { Uso de pañal, diarrea o } \\
\text { incontinencia }\end{array}$ & $\mathrm{C}$ & $\begin{array}{l}\text { Menores de } 3 \text { años durante toda la } \\
\text { hospitalización. } \\
3 \text { a } 14 \text { años, incluso dos semanas des- } \\
\text { pués de la aparición de los síntomas. } \\
\text { Mayores de } 14 \text { años, } 1 \text { semana des- } \\
\text { pués de la aparición de los síntomas }\end{array}$ & $\begin{array}{l}\text { En pacientes menores de } 3 \text { años que con- } \\
\text { trolan esfínteres y ya no evacúan, puede } \\
\text { evaluarse el retiro }\end{array}$ \\
\hline $\begin{array}{l}\text { Virus del Herpes simple } \\
\text { mucocutáneo disemi- } \\
\text { nado }\end{array}$ & $\mathrm{C}$ & $\begin{array}{l}\text { Hasta que las lesiones se hayan } \\
\text { secado }\end{array}$ & Evaluar el aislamiento en neonatos \\
\hline $\begin{array}{l}\text { Virus inmunodeficien- } \\
\text { cia adquirida }\end{array}$ & $\mathrm{E}$ & No requiere aislamiento & $\begin{array}{l}\text { Precauciones estándar, manejo de secre- } \\
\text { ciones }\end{array}$ \\
\hline $\begin{array}{l}\text { Herpes Zoster disemi- } \\
\text { nado en todo paciente } \\
\text { En pacientes inmuno- } \\
\text { comprometidos caso } \\
\text { localizado o disemi- } \\
\text { nado }\end{array}$ & $\begin{array}{l}\text { Mixto (A } \\
+\mathrm{C})\end{array}$ & $\begin{array}{l}24 \text { horas posterior al secado de la } \\
\text { última lesión }\end{array}$ & $\begin{array}{l}\text { Se recomienda que el personal de salud } \\
\text { susceptible no tenga contacto con estos } \\
\text { pacientes. }\end{array}$ \\
\hline $\begin{array}{l}\text { Herpes Zoster Pacientes } \\
\text { inmunodeprimidos } \\
\text { En contactos }\end{array}$ & $\begin{array}{l}\text { Mixto (A } \\
+\mathrm{C})\end{array}$ & 21 días & $\begin{array}{l}\text { Se recomienda que el personal de salud } \\
\text { susceptible no tenga contacto con estos } \\
\text { pacientes. }\end{array}$ \\
\hline $\begin{array}{l}\text { Herpes Zoster loca- } \\
\text { lizado en pacientes } \\
\text { inmunocompetentes }\end{array}$ & $\mathrm{E}$ & No requiere aislamiento & $\begin{array}{l}\text { Se recomienda que el personal de salud } \\
\text { susceptible no tenga contacto con estos } \\
\text { pacientes, si hay disponibilidad de } \\
\text { personal }\end{array}$ \\
\hline $\begin{array}{l}\text { Influenza } \\
\text { caso }\end{array}$ & G & $\begin{array}{l}\text { Cinco días en pacientes con trata- } \\
\text { miento completo }\end{array}$ & $\begin{array}{l}\text { Trasportar al paciente con mascarilla } \\
\text { fuera del ambiente. Revisar que se admi- } \\
\text { nistren las dosis completas }\end{array}$ \\
\hline $\begin{array}{l}\text { Influenza } \\
\text { contacto }\end{array}$ & G & 7 días para contactos de influenza & $\begin{array}{l}\text { Evaluar uso de quimioprofilaxis dentro de } \\
\text { las } 48 \text { posteriores al contacto. }\end{array}$ \\
\hline $\begin{array}{l}\text { Encefalitis y meningitis } \\
\text { bacteriana, micótica, } \\
\text { tuberculosa, viral, } S \text {. } \\
\text { pneumoniae, aséptica }\end{array}$ & $\mathrm{E}$ & No requiere aislamiento & \\
\hline $\begin{array}{l}\text { Meningococo (Neisse- } \\
\text { ria meningitidis), sepsis, } \\
\text { neumonía, meningitis }\end{array}$ & G & $\begin{array}{l}\text { Hasta } 24 \text { horas de iniciar el trata- } \\
\text { miento }\end{array}$ & $\begin{array}{l}\text { Profilaxis al personal de salud en contac- } \\
\text { to cercano con secreciones y sin uso de } \\
\text { equipo protector, así como a contactos de } \\
\text { casa. Vacuna solo en caso de brotes }\end{array}$ \\
\hline $\begin{array}{l}\text { Mycoplasma pneumo- } \\
\text { niae }\end{array}$ & G & Duración de la enfermedad & \\
\hline $\begin{array}{l}\text { Neumonía por adeno- } \\
\text { virus en brotes } \\
\text { En situación normal }\end{array}$ & G & $\begin{array}{l}\text { Duración de la enfermedad. } \\
\text { No requiere aislamiento }\end{array}$ & En brotes \\
\hline $\begin{array}{l}\text { Parotiditis } \\
\text { caso }\end{array}$ & G & $\begin{array}{l}\text { Hasta cinco días después de la infla- } \\
\text { mación de parótidas }\end{array}$ & \\
\hline $\begin{array}{l}\text { Parotiditis } \\
\text { contacto }\end{array}$ & G & Período de incubación hasta 14 días & $\begin{array}{l}\text { Profilaxis al personal de salud en contac- } \\
\text { to con secreciones y sin uso de equipo } \\
\text { protector, así como a contactos de casa. } \\
\text { Vacuna Tdap para adultos }\end{array}$ \\
\hline
\end{tabular}




\begin{tabular}{|c|c|c|c|}
\hline $\begin{array}{l}\text { Parvovirus B19 } \\
\text { caso }\end{array}$ & G & $\begin{array}{l}\text { No requiere aislamiento al aparecer } \\
\text { exantema en pacientes inmunocom- } \\
\text { petentes }\end{array}$ & $\begin{array}{l}\text { Retirar aislamiento al iniciar el exantema. } \\
\text { En pacientes que presenten crisis aplásica } \\
\text { transitoria aislamiento durante } 7 \text { días. } \\
\text { En infección crónica, en inmunodeprimi- } \\
\text { dos, mantener aislamiento hasta su egreso }\end{array}$ \\
\hline $\begin{array}{l}\text { Parvovirus B19 con- } \\
\text { tacto }\end{array}$ & G & $\begin{array}{l}\text { En pacientes con contacto iniciar } \\
\text { aislamiento dos días previos a la apa- } \\
\text { rición del exantema del caso e iniciar } \\
\text { desde el primer día en inmunocom- } \\
\text { prometidos. }\end{array}$ & Aislamiento por 10 días \\
\hline Pediculosis & $\mathrm{C}$ & $\begin{array}{l}\text { Hasta } 24 \text { horas de iniciado el trata- } \\
\text { miento }\end{array}$ & Revisar si tiene liendres \\
\hline $\begin{array}{l}\text { Pertussis } \\
\text { caso }\end{array}$ & G & $\begin{array}{l}5 \text { días posteriores al tratamiento anti- } \\
\text { biótico (macrólidos) o } 21 \text { días desde } \\
\text { el inicio del cuadro sin tratamiento }\end{array}$ & \\
\hline $\begin{array}{l}\text { Pertussis } \\
\text { contacto }\end{array}$ & G & Periodo de incubación 10 días & Valorar el inicio de la profilaxis \\
\hline $\begin{array}{l}\text { Rubeola } \\
\text { caso }\end{array}$ & G & $\begin{array}{l}\text { Hasta } 7 \text { días después de aparecer el } \\
\text { exantema }\end{array}$ & $\begin{array}{l}\text { Los trabajadores de salud susceptibles } \\
\text { no deben ingresar a la habitación si hay } \\
\text { cuidadores inmunes disponibles. Las mu- } \\
\text { jeres embarazadas que no son inmunes } \\
\text { no deben cuidar a estos pacientes. }\end{array}$ \\
\hline $\begin{array}{l}\text { Rubeola } \\
\text { contacto }\end{array}$ & G & $\begin{array}{l}\text { Durante el periodo de incubación a } \\
\text { contactos } 12 \text { días }\end{array}$ & $\begin{array}{l}\text { Administrar la vacuna tres días después } \\
\text { de la exposición en mujeres susceptibles } \\
\text { no embarazadas. Excluir al personal sani- } \\
\text { tario susceptible del servicio desde el día } \\
5 \text { después de la primera exposición hasta } \\
\text { el día } 21 \text { después de la última exposi- } \\
\text { ción, independientemente de la vacuna } \\
\text { posterior a la exposición. }\end{array}$ \\
\hline $\begin{array}{l}\text { Salmonella spp en } \\
\text { sangre u otro tejido }\end{array}$ & $\mathrm{E}$ & No se requiere aislamiento & \\
\hline $\begin{array}{l}\text { Sarampión } \\
\text { caso }\end{array}$ & A & $\begin{array}{l}\text { Hasta } 4 \text { días de iniciado el exantema } \\
\text { o durante la enfermedad en inmuno- } \\
\text { comprometidos }\end{array}$ & $\begin{array}{l}\text { El personal de salud susceptible no debe } \\
\text { tener contacto con los pacientes. }\end{array}$ \\
\hline $\begin{array}{l}\text { Sarampión } \\
\text { contacto }\end{array}$ & A & $\begin{array}{l}\text { Periodo de incubación a las pacientes } \\
\text { que estuvieron en contacto con el } \\
\text { caso } 12 \text { días }\end{array}$ & $\begin{array}{l}\text { Para pacientes susceptibles expuestos, } \\
\text { vacuna post-exposición dentro de las } 72 \\
\text { horas o inmunoglobulina dentro de los } 6 \\
\text { días cuando esté disponible. }\end{array}$ \\
\hline Sarna-escabiasis & $\mathrm{C}$ & Hasta $24 \mathrm{~h}$ de iniciado el tratamiento & \\
\hline $\begin{array}{l}\text { Sífilis congénita lesio- } \\
\text { nes abiertas húmedas } \\
\text { y con sangre en sífilis } \\
\text { primaria y secundaria } \\
\text { con lesiones cutáneas o } \\
\text { mucosas }\end{array}$ & $\mathrm{C}$ & $\begin{array}{l}\text { Hasta } 24 \text { h después de iniciar el } \\
\text { tratamiento }\end{array}$ & $\begin{array}{l}\text { Vigilar si aparece chancro durante } 3 \\
\text { meses a las personas que hayan tenido } \\
\text { contacto con las lesiones }\end{array}$ \\
\hline $\begin{array}{l}\text { Virus sincitial respira- } \\
\text { torio }\end{array}$ & $\mathrm{E}$ & $\begin{array}{l}\text { No requiere aislamiento, excepto en } \\
\text { situaciones especiales }\end{array}$ & $\begin{array}{l}\text { Evaluar el aislamiento en niños pequeños } \\
\text { en caso de brote }\end{array}$ \\
\hline $\begin{array}{l}\text { Síndrome de piel escal- } \\
\text { dada estafilocócica }\end{array}$ & AP & Duración de la enfermedad & $\begin{array}{l}\text { Es una precaución de referencia acordada } \\
\text { con el INP }\end{array}$ \\
\hline $\begin{array}{l}\text { Streptococcus Beta } \\
\text { hemolítico del grupo } \\
\text { A absceso abundante } \\
\text { secreción }\end{array}$ & G & Hasta $24 \mathrm{~h}$ de iniciado el tratamiento & $\begin{array}{l}\text { Si el drenaje es abundante o no es conte- } \\
\text { nido por el apósito o vendaje }\end{array}$ \\
\hline
\end{tabular}




\begin{tabular}{|c|c|c|c|}
\hline $\begin{array}{l}\text { Tuberculosis pulmonar } \\
\text { o laríngea confirmada o } \\
\text { sospecha }\end{array}$ & A & $\begin{array}{l}\text { Las precauciones se suspenden cuan- } \\
\text { do el paciente mejore clínicamente } \\
\text { y tenga tres frotis de esputo consecu- } \\
\text { tivos negativos recolectados en días } \\
\text { separados } \\
\text { Uso mascarilla N95, mantener cerra- } \\
\text { da la puerta, cuarto individual }\end{array}$ & $\begin{array}{l}\text { Retirar el aislamiento, mínimo, dos sema- } \\
\text { nas después de concluir el tratamiento } \\
\text { satisfactoriamente } \\
\text { Retirar al descartar el diagnóstico. Para } \\
\text { neonatos y pacientes pediátricos y } \\
\text { adolescentes, tomar las precauciones } \\
\text { aerotransportadas hasta que se realice } \\
\text { el estudio epidemiológico y se descarte } \\
\text { la tuberculosis pulmonar activa en los } \\
\text { familiares que lo visitan. Los pacientes } \\
\text { pediátricos no requieren aislamiento por- } \\
\text { que no son bacilíferos (no expectoran) }\end{array}$ \\
\hline $\begin{array}{l}\text { Tuberculosis extra- } \\
\text { pulmonar con lesión } \\
\text { supurativa }\end{array}$ & A & $\begin{array}{l}\text { Suspender las precauciones solo } \\
\text { cuando el paciente mejore clínica- } \\
\text { mente, y el drenaje haya cesado o } \\
\text { se reporten tres cultivos negativos } \\
\text { consecutivos }\end{array}$ & $\begin{array}{l}\text { Examinar si existe tuberculosis pulmonar } \\
\text { activa } \\
\text { Usar mascarilla N95, mantener cerrada la } \\
\text { puerta, cuarto individual }\end{array}$ \\
\hline $\begin{array}{l}\text { Tuberculosis extrapul- } \\
\text { monar sin lesión supu- } \\
\text { rativa o meníngea }\end{array}$ & $A^{*}$ & $\begin{array}{l}\text { *Examinar si existe tuberculosis pulmo- } \\
\text { nar. Para bebés y niños, tomar las pre- } \\
\text { cauciones aerotransportadas hasta que } \\
\text { se realice el estudio epidemiológico y } \\
\text { se descarte la tuberculosis pulmonar } \\
\text { activa en los familiares visitantes. }\end{array}$ & $\begin{array}{l}\text { Al descartar tuberculosis pulmonar en } \\
\text { familiares y visitantes }\end{array}$ \\
\hline Varicela caso & Mixto $(A+C)$ & $\begin{array}{l}\text { Hasta que todas las lesiones están } \\
\text { secas y en fase de costra. } \\
\text { Si existe complicación con neumo- } \\
\text { nía en pacientes inmunodeprimidos } \\
\text { durante la enfermedad }\end{array}$ & $\begin{array}{l}\text { El personal de salud susceptible no debe } \\
\text { tener contacto con estos pacientes y } \\
\text { evaluar si se prolonga el aislamiento en } \\
\text { pacientes inmunodeprimidos }\end{array}$ \\
\hline Varicela contacto & Mixto $(A+C)$ & $\begin{array}{l}\text { Aplicar precauciones para las perso- } \\
\text { nas susceptibles expuestas y excluir a } \\
\text { los trabajadores de atención médica } \\
\text { susceptibles expuestos a partir de } \\
\text { octavo día, durante } 21 \text { días }\end{array}$ & $\begin{array}{l}\text { Proporcionar la vacuna posterior a la ex- } \\
\text { posición lo antes posible, en las primeras } \\
120 \text { horas ( } 5 \text { días), en personas expuestas } \\
\text { susceptibles. } \\
\text { En quienes la vacuna está contraindicada } \\
\text { (personas inmunocomprometidas, mujeres } \\
\text { embarazadas, recién nacidos cuyo inicio } \\
\text { de varicela de la madre es }<5 \text { días antes } \\
\text { del parto o dentro de las } 48 \text { horas poste- } \\
\text { riores al parto) aplicar inmunoglobulina } \\
\text { específica (VZIG), dentro de las } 96 \text { horas; } \\
\text { si no está disponible, use IVIG, después } \\
\text { de la primera exposición hasta } 21 \text { días } \\
\text { después de la última exposición o } 28 \text { si } \\
\text { recibió VZIG, independientemente de la } \\
\text { vacunación posterior a la exposición. }\end{array}$ \\
\hline
\end{tabular}

E: estándar, A: Aéreo, AP: Aislamiento Protector, C: Contacto, G: Gotas, IC: Inmunocomprometido, M: mixto.

Toda enfermedad que no venga en la tabla anterior se llevarán a cabo precauciones estándar. 
Cristerna-Tarrasa GH, et al. Infecciones asociadas con la atención en salud

Cuadro 4. Recomendaciones de aislamiento de microorganismos resistentes a múltiples fármacos

\begin{tabular}{|c|c|c|c|}
\hline Organismo & Indicación & PEA & Consideraciones \\
\hline $\begin{array}{l}\text { Bacterias resistentes a } \\
\text { carbapenémicos }\end{array}$ & $\begin{array}{l}\text { Por resistencia } \\
\text { antimicrobiana }\end{array}$ & $\mathrm{C}$ & Usualmente, durante toda la hospitalización \\
\hline MRSA & $\begin{array}{l}\text { Por resistencia } \\
\text { antimicrobiana }\end{array}$ & $\mathrm{C}$ & Solo en heridas con secreción abundante \\
\hline VRE & $\begin{array}{l}\text { Por resistencia } \\
\text { antimicrobiana }\end{array}$ & $\mathrm{C}$ & Solo en heridas con secreción abundante \\
\hline $\begin{array}{l}\text { Pacientes externos con } \\
\text { factores de riesgo-métodos } \\
\text { invasivos }\end{array}$ & $\begin{array}{l}\text { Aislamiento hasta } \\
\text { descartar el } \\
\text { microorganismo } \\
\text { resistente a múltiples } \\
\text { fármacos }\end{array}$ & $\mathrm{C}$ & $\begin{array}{l}\text { Aislar al ingreso. } \\
\text { Valoración por un infectólogo. } \\
\text { Obtener hemocultivo. } \\
\text { Continuar con el aislamiento hasta obtener el resultado del } \\
\text { hemocultivo o la indicación de infectología. } \\
\text { Retirar aislamiento cuando el servicio de Infectología conside- } \\
\text { re que no tiene factor de riesgo para colonización o infección } \\
\text { por microorganismos resistentes a múltiples fármacos. }\end{array}$ \\
\hline
\end{tabular}

Precauciones específicas de aislamiento (PEA); BLEE: $\beta$-lactamasa de espectro extendido; C: contacto, CRE: enterobacteria resistente a carbapenem; LCR: líquido cefalorraquídeo; MRSA: Staphylococcus aureus resistente a meticilina; VRE: Enterococcus resistente a vancomicina

Cuadro 5. Aislamiento protector (AP)

\begin{tabular}{|c|c|c|c|}
\hline Padecimiento & Indicación & $\begin{array}{l}\text { Precaución de } \\
\text { referencia }\end{array}$ & $\begin{array}{l}\text { Consideraciones } \\
\text { Uso de bata, mascarilla } \\
\text { quirúrgica-cubrebocas }\end{array}$ \\
\hline $\begin{array}{l}\text { Pacientes con } \\
\text { pérdida grave de } \\
\text { integridad de la } \\
\text { piel }\end{array}$ & $\begin{array}{l}\text { 1. Quemados (más de } 25 \% \text { de la superficie } \\
\text { corporal) } \\
\text { 2. Síndrome de Stevens-Johnson } \\
\text { 3. Necrólisis epidérmica tóxica (síndrome de Lyell) } \\
\text { 4. Epidermólisis bulosa grave } \\
\text { 5. Fascitis necrosante } \\
\text { 6. Pioderma gangrenoso } \\
\text { 7. Dermatosis ampollosas (Síndrome de Reiter) } \\
\text { 8. Síndrome de choque tóxico } \\
\text { 9. Pénfigo. Indicación del personal de Inmuno- } \\
\text { logía }\end{array}$ & AP & $\begin{array}{l}\text { Se requiere nota en el expedien- } \\
\text { te por el médico tratante para } \\
\text { mantener el aislamiento }\end{array}$ \\
\hline $\begin{array}{l}\text { Pacientes } \\
\text { Inmunodeprimidos }\end{array}$ & $\begin{array}{l}\text { 1. Neutropenia, menor de } 500 \text { neutrófilos; indi- } \\
\text { cación en guías } \\
\text { 2. Inmunodeficiencias primarias. Indicación } \\
\text { Inmunología } \\
\text { 3. Pacientes en tratamiento con quimioterapia } \\
\text { altamente aplasiante, con concentración de } \\
500 \text { neutrófilos. Indicación del servicio de } \\
\text { Hemato-oncología } \\
\text { 4. Inmunodeficiencias secundarias solo si son } \\
\text { valoradas e indicadas por el médico. Indica- } \\
\text { ción por parte del servicio de Inmunología e } \\
\text { Infectología }\end{array}$ & AP & $\begin{array}{l}\text { 1. Recuperación de neutrófilos } \\
\text { (después de confirmar una } \\
\text { concentración mayor de } 500 \\
\text { neutrófilos debe retirarse el } \\
\text { aislamiento). } \\
2 \text { y } 3 \text {. Se requiere nota en el ex- } \\
\text { pediente, por el médico tratan- } \\
\text { te para mantener aislamiento. } \\
\text { 4. Solo con indicación médica }\end{array}$ \\
\hline
\end{tabular}




\begin{tabular}{|c|c|c|c|}
\hline $\begin{array}{l}\text { Pacientes con tras- } \\
\text { plante de células } \\
\text { hematopoyéticas }\end{array}$ & $\begin{array}{l}\text { Pacientes con más de } 500 \text { neutrófilos en las si- } \\
\text { guientes circunstancias: } \\
\text { 1. Pretrasplante (periodo de preparación) } \\
\text { 2. Postrasplante ( } 30 \text { días, sin recuperación de } \\
\text { neutrófilos) } \\
\text { 3. Enfermedad injerto contra huésped (cutáneo } \\
\text { grave manejar como pérdida de la integridad } \\
\text { de la piel). } \\
\text { 4. Pacientes con infecciones respiratorias (virus } \\
\text { respiratorios diferentes al de la influenza). } \\
\text { Indicación UTCPH }\end{array}$ & AP & $\begin{array}{l}\text { Se requiere nota en el expedien- } \\
\text { te, por el médico tratante para } \\
\text { mantener aislamiento }\end{array}$ \\
\hline $\begin{array}{l}\text { Pacientes con } \\
\text { trasplante renal }\end{array}$ & $\begin{array}{l}\text { 1. Trasplante renal (el aislamiento se considera } \\
\text { con base al efecto inmunosupresor del tra- } \\
\text { tamiento que reciben y no por la cuenta de } \\
\text { leucocitos, la relación se debe a la respuesta } \\
\text { inmunodeficiente secundaria). Indicación del } \\
\text { Departamento de Nefrología }\end{array}$ & AP & $\begin{array}{l}\text { Durante el periodo pretransplan- } \\
\text { te, trasplante y postrasplante } \\
\text { hasta su egreso } \\
\text { Se requiere nota en el expedien- } \\
\text { te, por el médico tratante para } \\
\text { mantener aislamiento }\end{array}$ \\
\hline
\end{tabular}

AP: Aislamiento protector, EIH: Enfermedad de injerto contra huésped, NT: Neutrófilos totales, UTCPH: Unidad de Trasplante de Células Progenitoras Hematopoyéticas

guro (limpieza, desinfección, cambio de filtros de aire acondicionado, limpieza de ductos de aire y rejillas, reparación y mantenimiento de tuberías, cisternas, sistemas de enfriamiento), pues de no contar con la garantía de un adecuado manejo de todos estos elementos, deberán modificarse las políticas de aislamiento y tornarse más estrictas en su implementación y establecer un periodo más prolongando para tratar de minimizar los riesgos de transmisión de microorganismos. El pilar fundamental para disminuir las infecciones asociadas con la atención en salud es la higiene de manos en los cinco momentos de atención al paciente, y la desinfección del material y equipo médico. El adecuado apego a estas medidas se traduce en una atención médica humana y de alta calidad.

\section{REFERENCIAS}

1. Infection prevention and control in health care. Disponible en: http://www.who.int/csr/bioriskreduction/infection control/en/index.html

2. Haque $M$, Sartelli M. Health care-associated infections: an overview. Infection and Drug Resistance. 2018;11:23212333. https://doi.org/10.2147/IDR.S177247

3. $\mathrm{CDC} / \mathrm{NHSN}$ Surveillance Definition of Healthcare-Associated Infection and Criteria for Specific Types of Infections in the Acute Care Setting. http://www.socinorte.com/ wp-content/uploads/2013/03/Criterios-de-IN-2013.pdf
4. Mulani MS, Kamble EE, Kumkar SN, Tawre MS, Pardesi KR. Emerging Strategies to Combat ESKAPE Pathogens in the Era of Antimicrobial Resistance: A Review. Front Microbiol. 2019; 10 (539): 1-24. https://doi.org/10.3389/ fmicb.2019.00539

5. Biegel JD, Rhinehart E, Jackson $M$, Chiarello $L$, and the Healthcare Infection Control Practices Advisory Committee, 2007 Guideline for Isolation Precautions: Preventing Transmission of Infectious Agents in Healthcare Settings. https://www.cdc.gov/niosh/docket/archive/pdfs/NIOSH219/0219-010107-siegel.pdf

6. Iona Munjal Infection Control and Isolation Considerations for the Pediatric Practitioner Pediatrics in Review 2018;39;107. https://doi.org/10.1542/pir.2016-0110

7. Long S. Red Book 2018. $31^{\text {st }}$ ed. Elk Grove Village: American Academy of Pediatrics; 2018.

8. Sprague E, Reynolds S, Brindley P. Patient Isolation Precautions: Are They Worth It? Canadian Respiratory Journal, 2016. https://doi.org/10.1155/2016/5352625

9. Tuladhar E. Reducing viral contamination from finger pads: handwashing is more effective than alcohol-based hand disinfectants. J Hosp Infect. 2015; 90 (3): 226. https://doi. org/10.1016/j.jhin.2015.02.019

10. Nulens, Guide to infection control in the hospital; International Society of Infectious Diseases; Feb 2018. https://isid.org/wpcontent/uploads/2018/07/ISID_InfectionGuide_Chapter7.pdf

11. Banach DB, Bearman G, Barnden M, Hanrahan JA, et al. Duration of Contact Precautions for Acute-Care Settings. Infect Control Hosp Epidemiol 2018; 39 (2): 127-144. https://doi.org/10.1017/ice.2017.245

12. CDC. Interim Infection Prevention and Control Recommendations for Measles in Healthcare Settings. https://www. cdc.gov/infectioncontrol/guidelines/measles/index.html 